\title{
A Semi-Analytical Model of Cyclic Behavior of Reinforced Concrete Joints Rehabilitated with FRP
}

\author{
Abhijit Mukherjee ${ }^{1, *}$ and Kamal Kant Jain ${ }^{2}$ \\ ${ }^{1}$ Institute Chair Professor (Civil Engineering) and Dean Research and Development, \\ Indian Institute of Technology (IIT) Gandhinagar, Ahmedabad (Gujarat), India. \\ ${ }^{2}$ Research Scholar, Department of Civil Engineering, Indian Institute of Technology (IIT) Delhi, New Delhi, India.
}

(Received: 18 October 2012 Received revised form: 28 July 2013; Accepted: 7 October 2013)

\begin{abstract}
This paper presents a semi-analytical model for damaged reinforced concrete (RC) beam-column joints that are restored with fiber reinforced polymers (FRP). Constituent materials are characterized by their stress-strain curves. Confinement to concrete offered by the FRP is discussed. Stress-strain behavior of control and yielded steel bars and FRP laminate are presented. Material properties are utilized to develop the cross-sectional model in the form of moment-curvature $(M-\phi)$ relationships. Effect of confinement and longitudinal FRP reinforcement on momentcurvature relationships is discussed. Cross sectional properties are extended to obtain the load-displacement relationships of the beam-column joints. A softening model is developed to incorporate the progressive damage of the joint. Variations of softening coefficient with displacement cycles, displacement history and confinement are reported. Models presented are validated using experimental results.
\end{abstract}

Key words: fiber composites, beam-column joints, stiffness degradation, cyclic loads, load-displacement.

\section{INTRODUCTION}

Reinforced concrete (RC) construction is one of the most widely used construction methods. A series of earthquakes (the watershed was arguably the 1971 San Fernando earthquake) exposed their vulnerability at the beam-column joints. The ductile beam-column construction technique developed to alleviate the problem has gradually been adopted in the building codes all over the world. However, large stocks of structures that are built earlier need retrofitting. Consequent to ground motion, large shear forces and bending moments are developed at the joint. High bending moments may cause yielding or buckling of the steel reinforcements leading to large cracks. High compressive stress in concrete may lead to its crushing. Due to poor confinement, the concrete joint may disintegrate and concrete may spall. Insufficient shear reinforcement may cause diagonal cracks near joints. The damages at joints may result in the formation of plastic hinges. If the number of hinges in the structure exceeds its stability limit the entire structure collapses.

Aim of structural retrofits is to enhance the ductility in the system. Ductile joints are able to withstand higher deformations before collapse. It is well known that proper reinforcement detailing can considerably enhance the ductility of joints. However, a large majority of built facilities have deficient reinforcement. The pitfalls of improper reinforcement detailing have been highlighted by many researchers. In the following discussion only key observations relevant to the present objectives have been included. The provision of adequate spirals or hoop reinforcements at critical sections was suggested for resisting the bursting pressure due to compression as well as the tension from the beam reinforcements (Hanson and Connor 1967; Hanson 1971; Lee et al. 1977).

Importance of bond between the longitudinal bars and concrete for the dissipation of energy has been highlighted (Durrani and Wight 1985; Filippou 
et al. 1986). The combined effect of joint shear and the compressive load on the column has been studied and it was observed that higher column compression delays shear cracking (Meinheit and Jirsa 1981; Clyde et al. 2000). Based on the experiments on a wide range of joints, it is observed that the small samples had faster deterioration of stiffness due to early loss of bond (Abrams 1987). Retrofitting deficient joints that have not been damaged prior to the retrofit has been investigated (Park and Ruitong 1998; Lowes and Moehle 1999; Dhakal et al. 2005). However, many structures need repair after suffering severe damage. Recently, rehabilitation technique for complete recovery of joints that have been damaged to the extent that beams had exhausted their moment resistance capacity has been reported (Mukherjee and Joshi 2005). Use of reinforced concrete jackets (Alcocer and Jirsa 1993) and steel plate jackets (Ghobarah et al. 1997) to strengthen the joints has been studied. However, execution of such rehabilitation is disruptive to the operation of the facility, is labor intensive and very time consuming. Application of FRP has promised to alleviate these difficulties. FRP in enhancement of bending and shear capacities of flexure elements (Triantafillou and Antonopoulos 2000) and enhancement of confinement of concrete in compression elements (Mukherjee et al. 2004) is well established. Some apprehensions have been expressed on the efficiency of FRP in mitigating such distresses in joints, because maintenance of the continuity of the fibers at the joints is difficult. In extreme load conditions, such as earthquake, ductility of the joint is required to delay their collapse. The brittleness of FRP is also considered a negative. However, creative applications of FRP can rectify these deficiencies. The lack of ductility of a joint with inadequately lapped reinforcements has been mitigated by a hybrid of Carbon Fiber reinforced Polymer (CFRP) sheets and steel angles and bolts (Geng et al. 1998). Improvement of the flexure capacity of elements framing into the joints has been reported (Parvin and Granata 2000) by glass, Kevlar and Carbon composites. Shear deficient frames have been strengthened by adhesively bonding CFRP strips and sheets on the external surfaces of flexure members (Antonopoulos and Triantafillou 2003) and a design methodology for such joints (Triantafillou and Antonopoulos 2000) has been proposed. Numerical models to predict the load-deflection behavior of RC joints have also been proposed (Antonopoulos and Triantafillou 2002). The combined shear deficiency and bond slip have been treated by a hybrid of steel anchors and CFRP sheets (Ghobarah et al. 2000; Ghobarah and El-Amoury 2005).
Reinforced beam-column joints when subjected to cyclic loads such as in case of earthquakes are susceptible to brittle failure. Lowes and Altoontash (2003) developed a model to represent the response of RC beam-column joints under reversed-cyclic loading. They developed a four-node 12-degree-offreedom element for use with typical hysteretic beamcolumn line elements in two-dimensional nonlinear analysis of reinforced concrete structures. Constitutive relationships were developed to define the load deformation response of the joint model on the basis of material, geometric, and design parameters. Mitra and Lowes (2004) modified this model to take into account the variation in tensioncompression couple distance, bond-slip constitutive law to ensure that strength degradation occurred only due to cyclic loading and anchorage length. Ghobarah and El-Amoury (2005) reported that rehabilitation of joints subjected to cyclic loads using FRP composites is effective in significantly increasing the joint energy dissipation and in reducing the joint stiffness degradation. It was also observed that rehabilitations lead to the change in the failure mode from brittle joint shear and steel bar bond slip to formation of ductile beam hinges.

In the presented work an attempt has been made to obtain cyclic load-displacement relations by means of a softening model, for FRP rehabilitated joints. Experimental work conducted has also been discussed in brief. Material and cross-sectional models used for development of the load-displacement relation are also discussed. Proposed structural model helps in obtaining the load displacement parameters at various distress levels i.e. in pre yield, post yield and softening zones for $\mathrm{RC}$ joints under cyclic loads. The method predicts the joint characteristics till failure that can be used in a variety of design techniques such as pushover analysis for earthquake resistant design. The analytical results have been validated with the experimental observations. Furthermore, the results provide an insight into the levels of strengthening achieved by a particular design using FRP. Hence, the models are useful in carrying out rehabilitation design for a targeted load-displacement performance.

\section{EXPERIMENTAL INVESTIGATIONS}

Only a brief summary of the experimental work carried out is presented in this paper as main focus of the present paper is on the analytical model. Detailed discussion on experimental study has been reported by Rai (2007). The present experiment has four stagesspecimen preparation, infliction of damage, rehabilitation and test of rehabilitated specimens. 


\subsection{Specimen Preparation}

The schematic configuration and dimensions of the joints are shown in Figure 1. All the specimens had identical dimensions. They had the same longitudinal reinforcements in the beams and columns. However, the spacing and the position of stirrups differed in the two sets. One set had closely spaced stirrups $(75 \mathrm{~mm})$ to provide adequate confinement and shear capacity. The stirrups were provided in the columns of the core joint region as per the contemporary ductile detailing practice (D-type). In the other set of specimens the spacing of stirrups is relatively sparse $(150 \mathrm{~mm})$ as per the older practice that would lead to brittle failure (B-type). In this case, there are no stirrups in the core joint region. While the first group of specimens should not fail in shear the second group is shear deficient i.e. their calculated shear strength is lower than their bending strength. The reinforcement cages were prepared taking care of the precise position of the longitudinal bars and stirrups. They were placed in steel molds and a cover of $20 \mathrm{~mm}$ was maintained by means of spacers. The specimens were demolded after 72 hours and kept in the curing tank for 28 days. The surface dried specimens were used in testing.

\subsection{Damage Infliction}

For damage infliction, the specimens were pinned at the ends of columns and a constant axial load (10\% of column capacity) was applied at the top of the column by means of a hydraulic jack. The magnitude of load was monitored
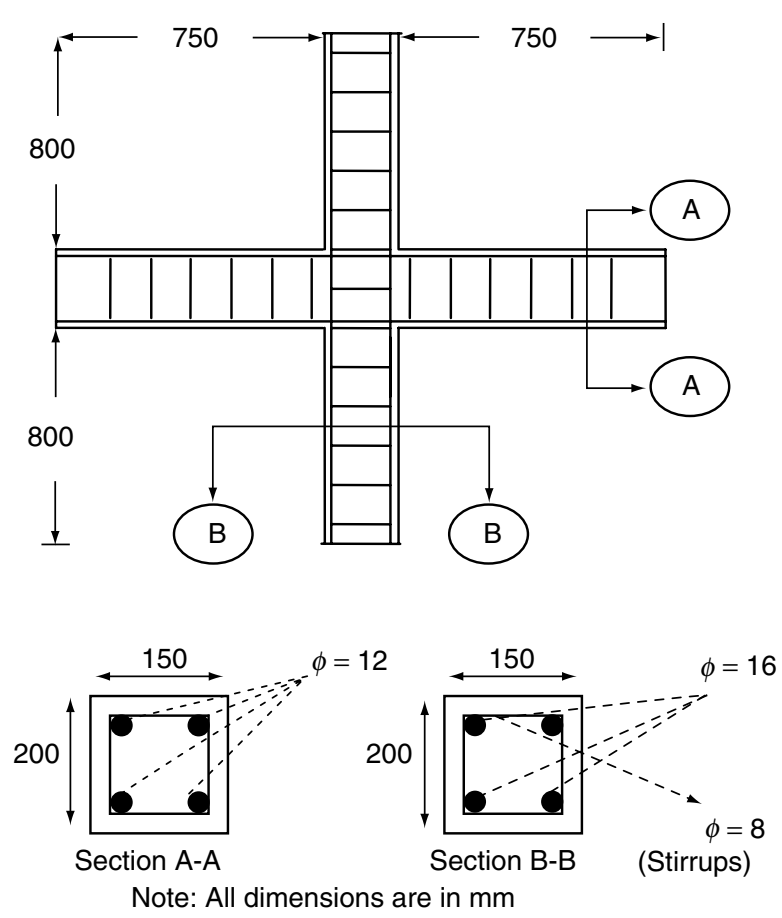

Figure 1. Reinforced concrete beam - column joint specimen

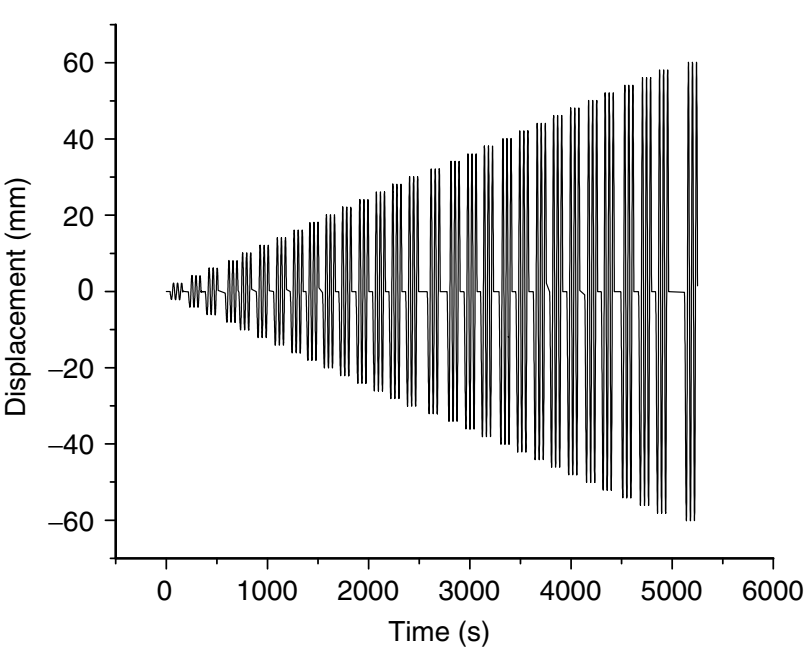

Figure 2. Imposed displacement cycles

through a load cell. To inflict damage, the joints were subjected to a displacement controlled experiment. Displacement was applied at the beam tip by attaching an actuator of $500 \mathrm{kN}$ capacity. The displacement consisted of an epoch of three identical load cycles starting from $2 \mathrm{~mm}$ amplitude and increasing at a rate of $2 \mathrm{~mm}$ in each consecutive epoch (as shown in Figure 2). The experiment was stopped when there was no more resistance offered by the joint. During the experiment both instrumental and visual records were maintained. Cracks on the surface of the specimens were marked at the completion of each load cycle and were traced on a grid. Differently colored lines (in Figure 3) indicate the paths of the cracks and the associated number indicates the level of corresponding tip displacement. The main observations are as follows:

(1) Brittle specimen suffered severe shear cracks and spalling of concrete.

(2) Concrete had spalled extensively in both brittle and ductile specimens.

(3) The longitudinal reinforcements in beams had yielded and in some cases ruptured. There was loss of bond between the concrete and the reinforcements.

\subsection{Specimen Rehabilitation}

For rehabilitation, damaged sections were rebuilt using fresh concrete, an epoxy mortar and a low viscosity grout. The damaged specimens were rebuilt using the following steps:

(1) Loose concrete was removed and the surfaces were cleaned of dirt.

(2) Areas where almost whole section had severe spalling were rebuilt with fresh concrete. Formwork was placed in the affected region and free flowing concrete was poured. 


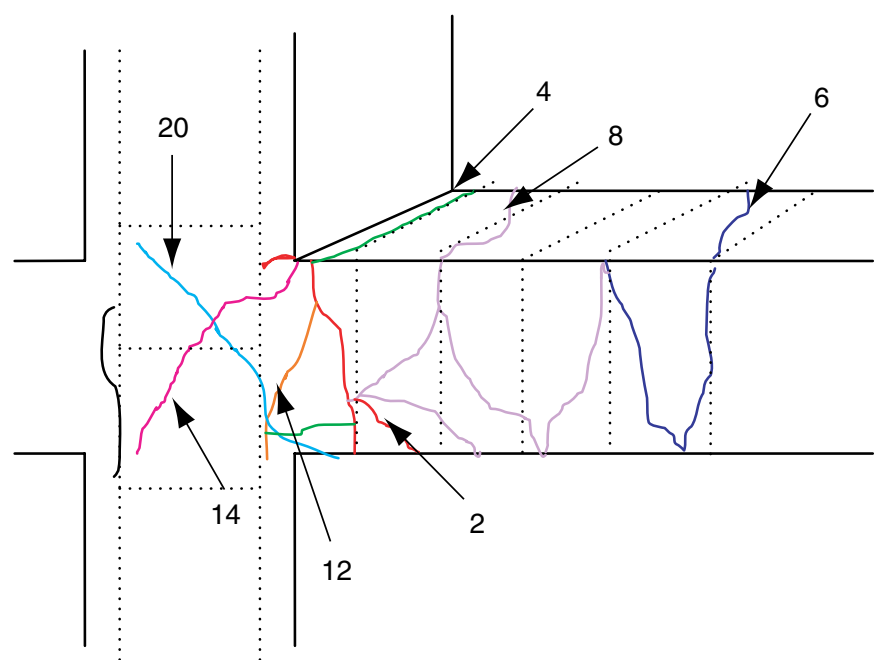

(a) D-Type

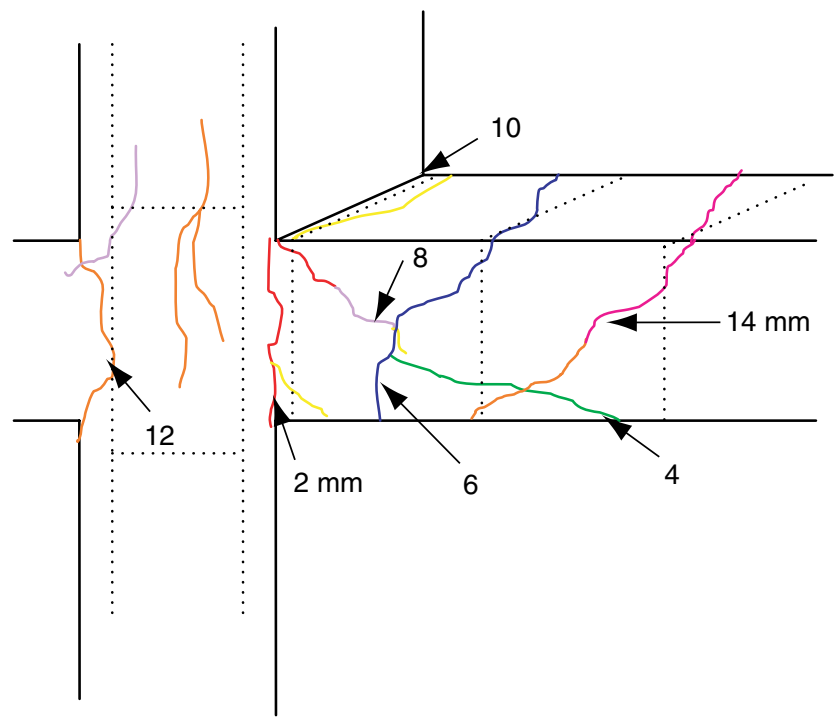

(b) B-Type

Figure 3. Cracks in D-Type and B-Type specimens
(3) Areas where there were large cracks but the concrete did not spall totally; epoxy mortar (one part epoxy with 5 parts quartz sand) was used to replace the lost concrete.

(4) Cracks of less than $1 \mathrm{~mm}$ width were filled with an epoxy resin of viscosity $100 \mathrm{cps}$ by pressure grouting.

(5) Concrete surface was smoothened by removing sharp protrusions (where the FRP is to be overlaid). Thixotropic epoxy filler was used in filling small dents.

(6) The corners were rounded off to a minimum radius of $15 \mathrm{~mm}$ and then the surfaces were dusted using dry cloth and then cleaned with acetone.

No additional steel reinforcement was provided to compensate for the yielded and ruptured reinforcement. FRP composite was used in two forms- composite plates (CP laminates) and composite sheets (CS wraps). Lack of confinement and shear capacity of the joints were compensated by CS wraps on both beams and columns (extended onto the joints). Precured unidirectional carbon fiber composite plates of $50 \mathrm{~mm}$ width that have one surface roughened for adhesive bonding with concrete was used as CP. It was used on both faces of the beam to compensate for the lost longitudinal reinforcement. On the other hand, CS was used as transverse reinforcement at the time of rehabilitation by wrapping them around the beams and column sections. The wraps need to be flexible and therefore are used in uncured form. FRP was applied in the following steps (Figure 4):

(1) CP attachment on beam: CP has been used on the top and bottom surfaces of the beams as tensile reinforcements. To anchor the $\mathrm{CP}$ at the joint, an incision of $5 \mathrm{~mm}$ thickness and $60 \mathrm{~mm}$

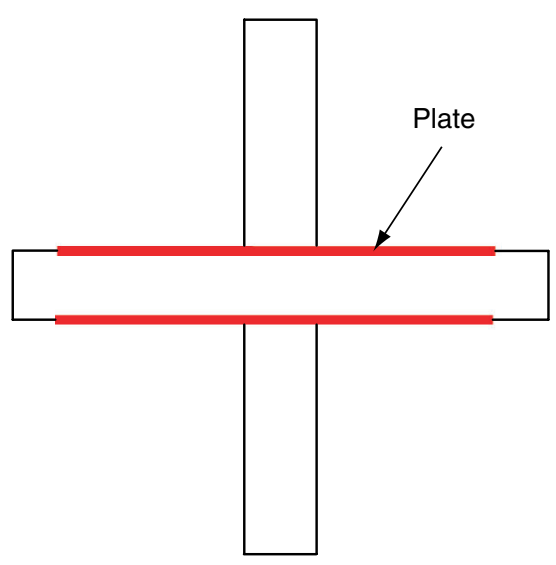

CP attachment

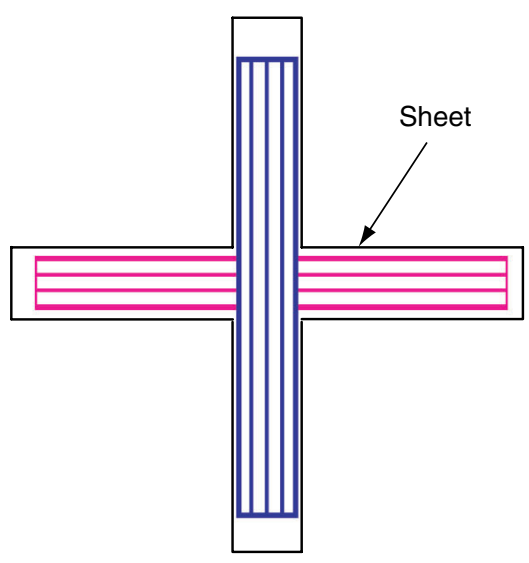

Longitudinal sheets

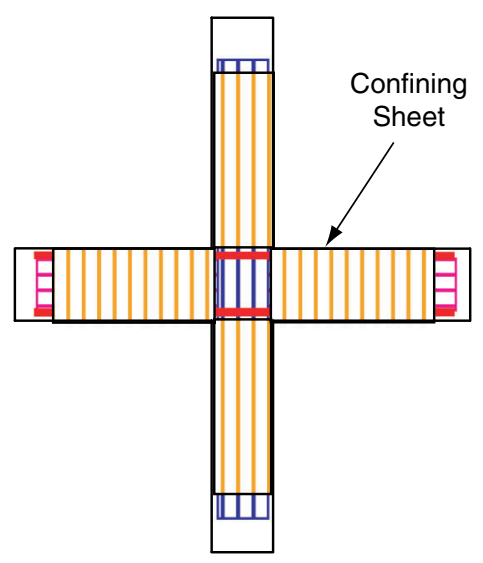

Transverse wrap around

Figure 4. Sequence of FRP application for rehabilitation 
width has been made in the column at the beam column interface. The groove is filled up with the adhesive and the $\mathrm{CP}$ is inserted into the groove. The epoxy was allowed to cure to obtain an end anchor.

(2) CS attachment: CS was used for the rest of the rehabilitation. CS was adhesively bonded to the faces of the column and the beam, with fiber direction along the axis of the elements.

(3) Wrapping beam and column with CS: Then beam and the column were wrapped with transverse CS to provide additional confinement.

\subsection{Test of Rehabilitated Specimens}

Rehabilitated specimens (both ductile and brittle type) were then subjected to the cyclic displacements as described in Section 2.2. The load-deflection characteristics of the joints were observed.

\section{ANALYTICAL INVESTIGATIONS}

\subsection{Material Model}

The response of a structure under load primarily depends on the stress-strain relation of its constituent materials. Hence, the constitutive relations of the materials i.e. concrete, steel reinforcements and CFRP wraps and strips must be defined.

\subsubsection{Concrete}

In context of this study, constitutive relation of concrete must consider the effect of confinement provided by steel and composites. Therefore, theoretical model to quantify confinement of concrete in bending compression reported by Mukherjee et al. (2009) is adopted in this work. The confinement factor $\left(C_{f}\right)$ is defined as a function of the relative stiffness of the confining material and the concrete core radius

$$
C_{f}=\left(\frac{E_{f} t_{f}+E_{s} t_{s}}{E_{0} r}\right)^{0.5}
$$

where, $E_{f}=$ Modulus of elasticity of fiber; $E_{s}=$ Modulus of elasticity of steel

$E_{0}=$ Initial modulus of elasticity of concrete;

$t_{f}=$ Thickness of FRP wrap;

$t_{s}=$ Effective thickness of confining steel reinforcement;

$r=$ Effective radius of concrete core

The concrete core radius is dependent on the smaller dimension of the rectangular concrete section (b) and the corner radius $\left(r_{c}\right)$.

$$
r=\frac{b}{2}+\frac{30}{e^{0.4 r_{c}-2}}
$$

The above expression is valid when the concrete section is rectangular and $r_{c} \geq 10 \mathrm{~mm}$.

The stress strain relation depends on the effective confinement, because limiting strain is defined in terms of confinement factor, i.e. $\varepsilon_{\lim }=$ Limiting strain $=$ $0.002 *\left(1+5 C_{f}\right)$.

The stress-strain relation is defined as:

$$
\sigma_{c}=E_{c} \varepsilon_{c}=\left[\left(1-\frac{\varepsilon_{c}}{\varepsilon_{\lim }}\right) E_{0}+\frac{\varepsilon_{c} f_{c k}}{\varepsilon_{\lim }^{2}}\right] \varepsilon_{c}
$$

Where $E_{c}=$ Secant modulus of concrete; $f_{c k}=$ Characteristic strength of concrete.

Level of confinement primarily depends on two factors- spacing of steel stirrups (dense or sparse) and thickness of FRP wrap. On increasing the wrap thickness confinement increases while increase in stirrup spacing leads to reduction in confinement. Specimens with varying stirrup spacing and wrap thickness are considered, and analytically obtained values of confinement factors $\left(C_{f}\right)$, maximum strains and maximum stresses are presented in Table 1. Strain capacity of reinforced concrete specimens increases by

Table 1. Effect of confinement on stress - strain relation of concrete

\begin{tabular}{lccccc}
\hline $\begin{array}{l}\text { Wrap } \\
\text { thickness } \\
(\mathbf{m m})\end{array}$ & $\begin{array}{c}\text { Stirrup } \\
\text { spacing } \\
(\mathbf{m m})\end{array}$ & $\begin{array}{c}\text { Confinement } \\
\text { factor } \\
\left(\boldsymbol{C}_{\boldsymbol{f}}\right)\end{array}$ & Max. strain & $\begin{array}{c}\text { Max. } \\
\text { stress } \\
(\mathbf{M P a})\end{array}$ & $\begin{array}{c}\text { Area under } \\
\text { stress- } \\
\text { strain curve } \\
(\mathbf{M P a})\end{array}$ \\
\hline 0 & 150 & 0.086 & 0.00412 & 29.47 & 0.081 \\
0 & 75 & 0.149 & 0.00465 & 33.32 & 0.103 \\
0.23 & 150 & 0.150 & 0.00467 & 33.42 & 0.104 \\
0.23 & 75 & 0.193 & 0.00506 & 36.21 & 0.122 \\
\hline
\end{tabular}


around $23 \%$ due to the combined effect of the wrap application and reduction in the stirrup spacing. The maximum stress also increased by the same percentage. As a result, the area under the stress-strain curve increases by around $50 \%$. This area is a direct measure of the increase in compressive force capacity of the section. These analytical results illustrate the enhancement of compression capacity of concrete due to the increase in confinement.

\subsubsection{Reinforcement steel}

The steel bars for both longitudinal and transverse reinforcement was tested for tensile capacity and had a yield stress of $500 \mathrm{MPa}$. Steel bars were extracted after infliction of damage from locations where gages had indicated strains beyond the yield point and were then tested on the universal testing machine. Typical stressstrain relationships for both fresh and yielded steel are presented in Figure 5. Analytically, these relationships are modeled separately for: (1) pre-yield; (2) yield zone; and (3) post-yield responses.

\subsubsection{FRP}

The FRP wraps and strips were tested for their strength properties as per ASTM D-3039 (2006), FRPs exhibit linear elastic stress strain relationship. Detailed properties are presented in Table 2.

\subsection{Cross Section Model}

The material constitutive model is then used in developing the cross-sectional model in the form of $M-\phi$ relationships. The model has the following assumptions:

(1) Euler-Bernoulli hypothesis, i.e. plane section before bending remain plane after bending;

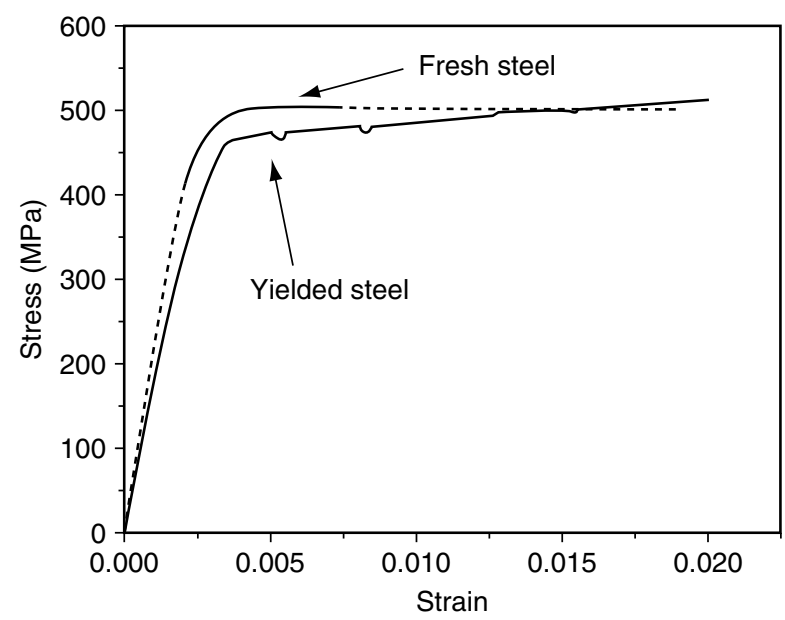

Figure 5. Stress-strain relation for fresh and yielded steel
Table 2. Properties of fiber reinforced polymer composites (FRPC)

\begin{tabular}{lcccc}
\hline $\begin{array}{l}\text { Material } \\
\text { (mm) }\end{array}$ & $\begin{array}{c}\text { Thickness } \\
\text { (mm) }\end{array}$ & $\begin{array}{c}\text { Tensile } \\
\text { strength } \\
\text { (GPa) }\end{array}$ & $\begin{array}{c}\text { Tensile } \\
\text { modulus } \\
\text { (GPa) }\end{array}$ & $\begin{array}{c}\text { Ultimate } \\
\text { strain }\end{array}$ \\
\hline $\begin{array}{l}\text { Carbon } \\
\begin{array}{l}\text { Wrap } \\
\text { Carbon }\end{array}\end{array}$ & 0.23 & 3.79 & 230 & 0.017 \\
Plate & 1.4 & 2.79 & 155.1 & 0.018 \\
\hline
\end{tabular}

(2) Effect of concrete in tension is neglected;

(3) Perfect bonding between all materials i.e. no bar slippage occurs;

(4) Displacements are small;

(5) Properties of steel in tension and compression are identical

\subsubsection{Proposed formulation}

For a given curvature, the magnitude of the strain in concrete $\left(\varepsilon_{c}\right)$, compression steel $\left(\varepsilon_{s c}\right)$, tension steel $\left(\varepsilon_{s t}\right)$, compression FRP $\left(\varepsilon_{c f}\right)$ and tension FRP $\left(\varepsilon_{t f}\right)$ are determined from the strain compatibility relations. For simplicity the strain in the FRP laminates are calculated on the surface of the beam, as its thickness is very small compared to the beam section. Depth of neutral axis $\left(X_{u}\right.$, from top of compression surface) for a given curvature is obtained by imposing the condition of equilibrium over the section. Compression force (C) and tension force $(\mathrm{T})$ are obtained as following:

$$
C=\sigma_{s c} A_{s c}+b \int_{0}^{X_{u}} \sigma_{c} d x+\sigma_{f c} A_{f c}
$$

where, $\sigma_{s c}, \sigma_{f c}$, and $\sigma_{c}$ are stresses respectively in compression steel, compression laminate, and concrete in compression; and $A_{s c}$ and $A_{f_{c}}$ represent cross sectional areas of compression steel and compression FRP respectively.

$$
T=\sigma_{s t} A_{s t}+\sigma_{t f} A_{t f}
$$

Where, $\sigma_{s t}, \sigma_{t f}$, are stresses respectively in tension steel and tension laminate. While $A_{s t}$, and $A_{f t}$ represent the cross sectional area of tension steel and tension FRP, respectively. After obtaining the depth of neutral axis, forces in concrete, FRP and steel are determined using material constitutive relationships. The moments of these forces about the neutral axis is obtained by the multiplication of forces and the 
corresponding lever arms. Resisting moment $(M)$ is then obtained by imposing moment equilibrium on the section, i.e. $M=M_{c}+M_{s c}+M_{s t}+M_{t f}+M_{c f}$; where, $M_{c}, M_{s c}, M_{f c}, M_{s t}$, and $M_{f t}$ are bending moments of resistance of compression concrete, compression steel, compression FRP, tension steel, and tension FRP respectively. The above procedure is adopted to obtain the $M-\phi$ relationship for the reinforced concrete sections. Eqn 4 and Eqn 5 are initially solved iteratively with a small value of $\phi$ and corresponding $M$. Subsequently, $\phi$ is increased with small steps (i.e. $\Delta \phi$ in the range of $\left.10^{-7} \mathrm{rad} / \mathrm{m}\right)$, till maximum allowable strain in concrete is reached. The gradient of the $M-\phi$ relation gives us the elastic tangent EI that includes all the section properties.

Using the cross section model, various $M-\phi$ relationships are obtained to analyze the effect of the constituent parameters such as confinement and cross sectional area of laminate on moment curvature relationship. It is observed from the obtained $E I$ values that the exponential function can be assumed to generalize the decrease in tangent $E I$ corresponding to the increase in moment.

\subsubsection{Effect of confinement on $\mathrm{M}-\phi$ relationships}

Confinement can be varied by changing either thickness of the CS wrap or spacing between the stirrups. On increasing wrap thickness, confinement increases while on increasing spacing between the stirrups confinement decreases due to the reduced effective thickness of confining steel.

(1) Effect of wrap thickness:

The confinement of concrete can be enhanced by the CS wrap. It may be recalled that the increase in confinement enhances compression capacity of concrete (Table 1). As a result, the section is capable of resisting higher bending moments. The curvature capacities also increase. However, the theoretical limit of confinement is reached when the steel reaches its yield point. The yielding of steel leads to the softening of the $M-\phi$ curve i.e. the section is under reinforced. As the present specimens are under-reinforced all of them have yielded at the same point. The failure occurs when concrete reaches its strain capacity. Table 3 summarizes bending moments and curvatures resulted for varying wrap thickness. The quantity of wrap is defined as area fraction of the wrap with respect to the area of the concrete section. For all these cases (Table $3)$, stirrup spacing $(75 \mathrm{~mm})$ and laminate area $\left(70 \mathrm{~mm}^{2}\right)$ are kept constant. Graphical presentation of the effect of varying wrap thickness on moment-curvature relation is reported in Figure 6(a). The bending moments and curvatures at yield remain unaffected by the wrap. However, their maximum values increase with the application of wraps. The ductility ratio has been computed as the ratio of maximum curvature and that at yield. Application of $0.69 \mathrm{~mm}$ thick wrap has increased the ductility ratio by about $28 \%$. This demonstrates that for an under reinforced section, increase in confinement increases ductility; i.e. the larger the wrap thickness more ductile is the behavior of the system.

(2) Effect of stirrups Spacing:

The spacing of stirrup has been varied between $75 \mathrm{~mm}$ to $150 \mathrm{~mm}$. To generalize the observations, the area of the stirrup has been expressed as area fraction of the cross-section area of the concrete section. The results for the various stirrup spacing have been summarized in Table 4. For all these cases the wrap thickness $(0.23 \mathrm{~mm})$ and the laminate area $\left(70 \mathrm{~mm}^{2}\right)$ are kept constant. Graphical presentation of the effect of varying stirrup spacing on moment-curvature relation is reported in Figure 6(b). As the stirrup spacing decreases i.e. as the stirrup area fraction increases, the capacity of the section, both in moment and curvature improves. It may be noted that the section is under-reinforced and the yield moment is independent of stirrup spacing. However, the ductility ratio of the section increases with reduction in stirrup spacing. There was a $10 \%$ increase in the ductility ratio with the stirrup spacing decreasing from $150 \mathrm{~mm}$ to $75 \mathrm{~mm}$.

Table 3. Effect of wrap thickness on $M-\phi$ relationship

\begin{tabular}{|c|c|c|c|c|c|c|c|}
\hline \multicolumn{3}{|c|}{ Wrap } & \multirow{2}{*}{\multicolumn{2}{|c|}{ B. M. (kN-m) }} & \multirow{2}{*}{\multicolumn{2}{|c|}{ Curvature $(\phi)(\mathrm{rad} / \mathrm{m})$}} & \multirow{3}{*}{$\begin{array}{c}\text { Ductility ratio } \\
\phi_{\max } / \phi_{\text {yield }}\end{array}$} \\
\hline \multirow{2}{*}{$\begin{array}{l}\text { Thickness } \\
\text { (mm) }\end{array}$} & \multirow{2}{*}{$\begin{array}{l}\% \text { Area } \\
\text { fraction }\end{array}$} & \multirow{2}{*}{$\begin{array}{c}\text { Confinement } \\
\text { factor }\left(C_{f}\right)\end{array}$} & & & & & \\
\hline & & & Yield & Max. & Yield & Max. & \\
\hline 0 & 0.00 & 0.149 & 22.9 & 48.1 & $2.38 \mathrm{E}-05$ & $1.05 \mathrm{E}-04$ & 4.40 \\
\hline 0.23 & 0.54 & 0.193 & 22.9 & 51.7 & $2.38 \mathrm{E}-05$ & $1.16 \mathrm{E}-04$ & 4.89 \\
\hline 0.46 & 1.07 & 0.230 & 22.9 & 54.7 & $2.38 \mathrm{E}-05$ & $1.25 \mathrm{E}-04$ & 5.27 \\
\hline 0.69 & 1.61 & 0.261 & 22.9 & 57.3 & $2.38 \mathrm{E}-05$ & $1.33 \mathrm{E}-04$ & 5.61 \\
\hline
\end{tabular}




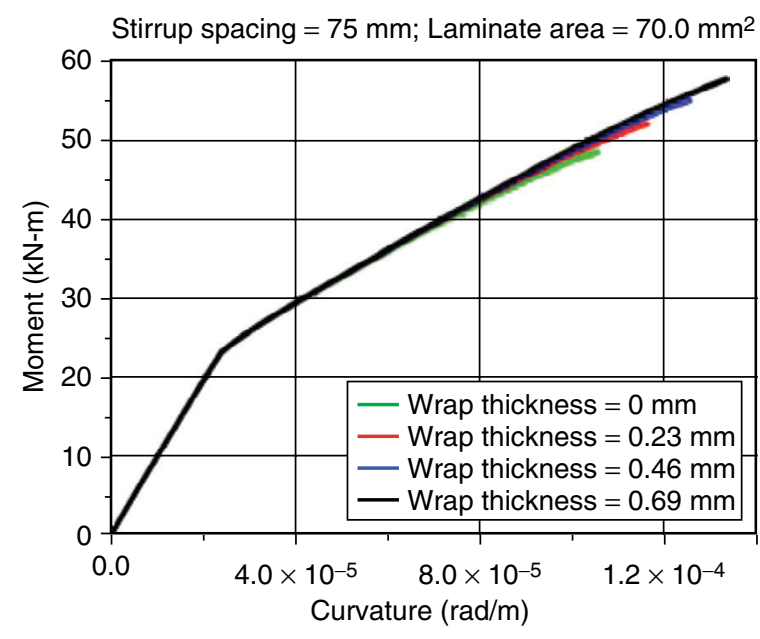

(a) Effect of variation in wrap thickness

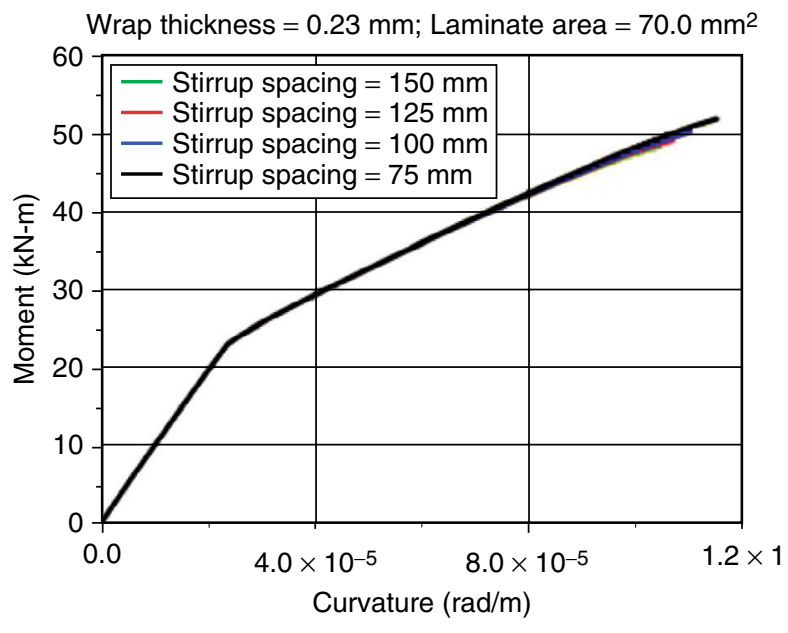

(b) Effect of variation in stirrup spacing

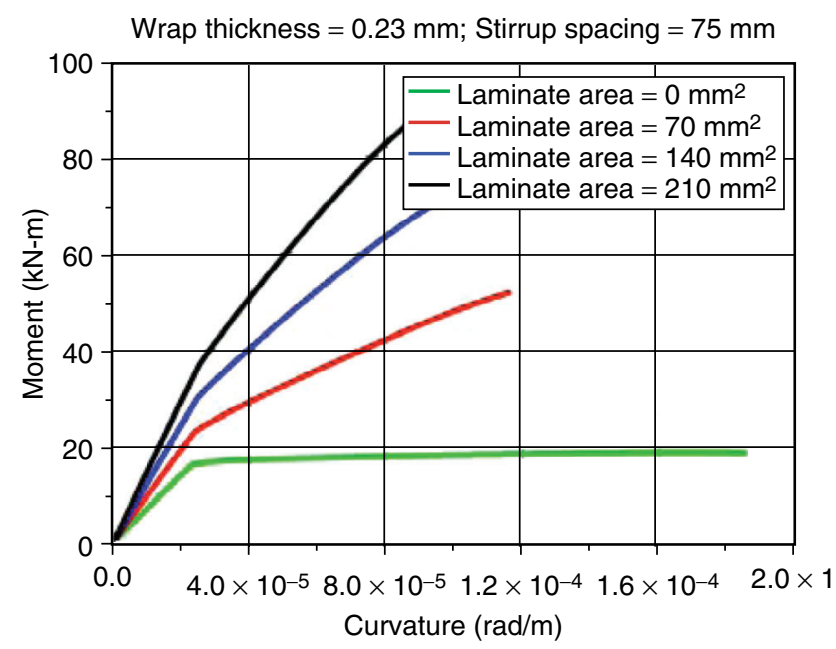

(c) Effect of variation in laminate area

Figure 6. Moment-curvature relationships

Table 4. Effect of stirrup spacing on M- $\phi$ relationship

\begin{tabular}{|c|c|c|c|c|c|c|c|}
\hline \multicolumn{3}{|c|}{ Stirrup } & \multirow{2}{*}{\multicolumn{2}{|c|}{ B. M. (kN-m) }} & \multirow{2}{*}{\multicolumn{2}{|c|}{ Curvature $(\phi)(\mathrm{rad} / \mathrm{m})$}} & \multirow{3}{*}{$\begin{array}{c}\text { Ductility ratio } \\
\phi_{\max } / \phi_{\text {yield }}\end{array}$} \\
\hline \multirow{2}{*}{$\begin{array}{l}\text { Spacing } \\
(\mathrm{mm})\end{array}$} & \multirow{2}{*}{$\begin{array}{l}\% \text { Area } \\
\text { fraction }\end{array}$} & \multirow{2}{*}{$\begin{array}{c}\text { Confinement } \\
\text { factor }\left(C_{f}\right)\end{array}$} & & & & & \\
\hline & & & \multicolumn{2}{|c|}{ 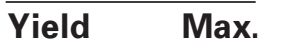 } & \multicolumn{2}{|c|}{$\begin{array}{ll}\text { Yield } \quad \text { Max. }\end{array}$} & \\
\hline 150 & 0.45 & 0.150 & 22.9 & 48.2 & $2.38 \mathrm{E}-05$ & $1.05 \mathrm{E}-04$ & 4.42 \\
\hline 125 & 0.54 & 0.160 & 22.9 & 49.0 & $2.38 \mathrm{E}-05$ & $1.08 \mathrm{E}-04$ & 4.52 \\
\hline 100 & 0.67 & 0.173 & 22.9 & 50.1 & $2.38 \mathrm{E}-05$ & $1.11 \mathrm{E}-04$ & 4.67 \\
\hline 75 & 0.89 & 0.193 & 22.9 & 51.7 & $2.38 \mathrm{E}-05$ & $1.16 \mathrm{E}-04$ & 4.89 \\
\hline
\end{tabular}

A comparison between the ductility ratios of sections with lower stirrup spacing and CFRP wraps can be made by comparing the last columns of Tables 3 and 4 . Benefit of lower stirrup spacing is far less spectacular than that of fiber wrapping. It was also observed in the experiments that specimens with wraps performed superior to the specimens with lower stirrup spacing. In past, similar observations have also been made through experimental studies (Sheikh and Yau 2002; Iacobucci et al. 2003).

\subsubsection{Effect of longitudinal reinforcement on $M-\phi$ relationships}

The $M-\phi$ relationship is also dependent on the longitudinal reinforcement provided in the beam. In the present investigation, the additional longitudinal 
Table 5. Effect of cross-section area of laminate on $\boldsymbol{M}-\phi$ relationship

\begin{tabular}{|c|c|c|c|c|c|c|c|}
\hline \multirow{3}{*}{$\begin{array}{c}\text { Area } \\
\left(\mathrm{mm}^{2}\right)\end{array}$} & \multicolumn{2}{|c|}{ Laminate } & \multirow{2}{*}{\multicolumn{2}{|c|}{ B. M. $(k N-m)$}} & \multirow{2}{*}{\multicolumn{2}{|c|}{ Curvature $(\phi)(\mathrm{rad} / \mathrm{m})$}} & \multirow{3}{*}{$\begin{array}{c}\text { Ductility ratio } \\
\phi_{\max } / \phi_{\text {yield }}\end{array}$} \\
\hline & \multirow{2}{*}{$\begin{array}{l}\% \text { Area } \\
\text { fraction }\end{array}$} & \multirow{2}{*}{$\begin{array}{c}\text { Confinement } \\
\text { factor }\left(C_{f}\right)\end{array}$} & & & & & \\
\hline & & & Yield & Max. & Yield & Max. & \\
\hline 0 & 0.00 & 0.193 & 16.0 & 18.6 & $2.29 \mathrm{E}-05$ & $1.85 \mathrm{E}-04$ & 8.08 \\
\hline 70 & 0.23 & 0.193 & 22.9 & 51.7 & $2.38 \mathrm{E}-05$ & $1.16 \mathrm{E}-04$ & 4.89 \\
\hline 140 & 0.47 & 0.193 & 29.9 & 71.0 & $2.45 \mathrm{E}-05$ & $9.63 \mathrm{E}-05$ & 3.93 \\
\hline 210 & 0.70 & 0.193 & 37.0 & 86.8 & $2.52 \mathrm{E}-05$ & $8.64 \mathrm{E}-05$ & 3.43 \\
\hline
\end{tabular}

reinforcement has been provided in the form of CFRP laminates on both top and bottom faces of the beam. The area of the CFRP laminates was varied from 0 to $210 \mathrm{~mm}^{2}$. To generalize the observations, the area of the laminate has been expressed as a fraction of the crosssectional area of the beam. The results for the various laminate areas have been summarized in Table 5. For all these cases wrap thickness $(0.23 \mathrm{~mm})$ and stirrup spacing $(75 \mathrm{~mm})$ are kept constant. Graphical presentation of the effect of varying stirrup spacing on moment-curvature relation is reported in Figure 6(c). The original beam was under-reinforced, and therefore had a ductile behavior. As the laminate area fraction increases the section exhibited higher initial stiffness and higher yield moment. This is due to the addition of CFRP in the tension area of the section. The post-yield behavior of the section was altered significantly with the addition of CFRP laminates. The CFRP is brittle and remains elastic until failure. Therefore, it continues to resist bending moment even after the steel reinforcement has yielded. However, with the increase of tension reinforcement the concrete in compression fails. Although the ultimate moments increased significantly with the addition of CFRP the ultimate curvatures reduced significantly. It may also be noted that the elastic stiffness of the beam doubled with the addition of $210 \mathrm{~mm}^{2}$ of CFRP. The ultimate moment increased by a factor of 4.7. Therefore, the moment capacity of the beam increases with the addition of CFRP. However, the casualty was the curvature capacity that reduced drastically with the addition of CFRP laminate. As a result, ductility ratio decreased more than 55\% due to addition of CFRP. Therefore, we may conclude that, the addition of longitudinal CFRP would improve the initial stiffness and moment carrying capacity of the section. However, it would have an adverse effect on ductility. Therefore, to design an effective retrofit for a structure judicious combination of longitudinal plates (laminates) and transverse sheets (wraps) must be made to meet the targets of initial stiffness, ultimate moment, curvature capacities and ductility ratios.

\subsection{Structural Model}

The results of the cross-section model have been used in the structural model. In this case the structure is a beam column joint (Figure 1). However, similar procedure can be followed to model structures consisting of several joints. Total displacement $(\delta)$ of the tip of the beam in a joint, due to a static load consists (is sum) of the displacements from flexural deformations of the beam, shear deformations of the beam, axial deformations of the column, and deformations due to the rotation of the column. Total strain energy $(U)$ of the system can be written as the sum of flexural strain energy $\left(U_{1}\right)$, shear strain energy $\left(U_{2}\right)$ and axial strain energy $\left(U_{3}\right)$, which are given as:

$$
\begin{gathered}
U_{1}=\int_{0}^{L} \frac{\{P(L-x)\}^{2}}{2 E I} d x+\int_{-L c}^{L c} \frac{P L^{*} m_{c}(y)}{2 E I_{c}} d y \\
U_{2}=\int_{0}^{L} \frac{P^{2}}{2 G A_{s}} d x \\
U_{3}=\int_{-L c}^{L c} \frac{P_{c}^{2}}{2 E A_{c}} d y
\end{gathered}
$$

Displacements can then be obtained by using the Castgliano's displacement theorem, which states:

$$
\delta_{p}=\frac{\partial U}{\partial P}
$$

where $\delta_{p}=$ Tip deflection in direction of $P$

$P=$ Load on the beam tip; $P_{c}=$ Axial load in column; $L=$ Length of beam

$E$ = Elastic modulus; $G=$ Shear modulus

$I=$ Area moment of inertia of beam; $I_{c}=$ Area moment of inertia of column

$A_{c}=$ Cross sectional area of column; $A_{s}=$ Effective c/s area of beam in shear 


\section{$m_{c}(y)=$ Functional variation of moment on column for unit moment at joint-column interface}

The parameters $E I, G A_{s}$ and $E A_{c}$ are functions of material and cross-sectional properties. As the joint experiences higher deformations, cracks develop and the structure loses stiffness. Initially, concrete fails in tension resulting in cracks at the top and bottom areas of the beam where the bending stresses predominate. The effect is loss of bending stiffness. In addition, as the deformation increases the bond between concrete and rebar is affected and bond slip occurs. Bond slip results in either widening of existing bending cracks or appearance of new bending cracks. Thus, the member loses bending stiffness at a higher rate. Hence, the bond slip can be modeled through reduction of bending stiffness. The members also deform in shear as manifested by shear cracking. The shear deformation is determined by the confinement of concrete. In addition, the joint area between the beam and the column deforms. The rectangular joint area gets deformed into a parallelogram manifesting its shear dominant deformation. At higher levels of deformation shear cracks appear in joints. The joint deformation can thus be modeled as loss of shear stiffness of the member. In extreme situations the rebars and the FRP may also rupture. It is a challenge to model the damaged state accurately. There are two approaches for such modeling- Fracture Mechanics Approach (FMA) and Damage Mechanics Approach (DMA). While FMA attempts to map individual cracks the DMA considers the fused cracks state that results in softening of the material. In this paper, cohesive DMA has been used. Using the cross section model described earlier the tangent moduli of the materials have been found and an incremental solution of Eqn 9 has been obtained.

\subsubsection{Cohesive damage model}

In the initial stages of loading (application to predetermined displacement regime) the beam is undamaged. As the joint is subjected to higher displacements the damage initiates at the root of the beam. Then it spreads towards the tip along the length of the beam. It is important to identify the zone of damage and its extent. The curvature at which the yielding starts (Tables 3-5) is considered as the onset of damage. Higher curvatures would cause further damage in the joint and that is manifested by softening. As the joint experiences higher displacement the onset point advances toward the tip. In the present model an exponential softening curve has been used. The combined effect of damage due to flexure and shear has been considered to calculate the load-displacement relationship of the joint. As explained earlier, bond slip and joint deformation effects are smeared in the EI and GA of the damaged zone. In addition to the assumption for cross-sectional model, structural cohesive damage model assumes the following:

(1) Displacements are small i.e. no geometric nonlinearity

(2) Displacement due to column axial deformation is negligible

(3) Bond slip manifests through additional reduction in $E I$

(4) Joint deformation manifests through additional reduction in $G A$

(5) Both $E I$ and $G A$ reduce exponentially in the damaged zone.

To calculate the incremental loads corresponding to the given incremental displacements an iterative method is used. The length of damage zone $\left(L_{d}\right.$ - i.e. the distance of the point on loaded beam from joint-beam interface up to the location at which bending moment in beam $M_{\text {beam }}$ equals yield moment $M_{\text {yield }}$ in a given step is considered as the initial estimate and the load is calculated. The length is revised based on the calculated tip load and an iterative procedure results.

The incremental load due to each incremental displacement is computed as $\Delta P_{i}=\left[k_{i}\right]^{*} \Delta \delta_{i}$. Total load and displacement at the beam tip, after the $i^{\text {th }}$ step are then computed respectively as; $P_{i}=P_{i-1}+\Delta P_{i}$ and $\delta_{i}=\delta_{i-1}+\Delta \delta_{i}$. Where, $\Delta P_{i}=$ Increment in load; $\Delta \delta_{i}=$ Increment in displacement; $\left[k_{i}\right]=$ Stiffness matrix; for $i^{\text {th }}$ step. As discussed earlier, the displacement at the beam tip consists of several components, which are computed using following formulations.

\subsubsection{Displacement due to bending of the beam}

The displacement is separately computed for damaged and undamaged parts of the beam.

(1) Displacement in the damaged part $\left(\Delta \delta_{i 1}\right)$

$$
\Delta \delta_{i 1}=\int_{0}^{L_{d}} \frac{\Delta P_{i}(L-x)^{2}}{E I(x)} d x
$$

$E I(x)$ varies exponentially and by applying the boundary conditions, $E I(0)=E I$ and $E I\left(L_{d}\right)=E I_{y}$; is determined as a function of $x$ (distance from joint face, up to damaged zone) as following:

$$
E I(x)=E I \cdot e^{\left(x / L_{d}\right) \cdot \ln \left(E I_{y} / E I\right)}
$$


where, $L=$ Length of beam; $L_{d}=$ Length of plastic hinge in beam; $E I_{y}=$ Flexural rigidity (Elastic); $E I=$ Flexural rigidity at joint-beam interface (Obtained using corresponding $M-\phi$ relation)

By substituting Eqn 11 in Eqn 10 and integrating, an explicit relationship can be obtained.

(2) Displacement in the undamaged part $\left(\Delta \delta_{i 2}\right)$

$$
\Delta \delta_{i 2}=\int_{L_{d}}^{L} \frac{\Delta P_{i}(L-x)^{2}}{E I_{y}} d x=\Delta P_{i}\left[\frac{\left(L-L_{d}\right)^{3}}{3 E I_{y}}\right]
$$

\subsubsection{Displacement due shear deformations in beam $\left(\Delta \delta_{i 3}\right)$}

Beam displacements due to shear deformations are calculated using Eqn 13 as following:

$$
\Delta \delta_{i 3}=\frac{\Delta P_{i}}{K_{s_{i}}}
$$

where $K_{s i}=$ Shear Stiffness of beam for $i^{\text {th }}$ step

Using the truss mechanism (Park and Paulay 1975) $K_{s i}$ is calculated as a function of the section and material properties. The involved parameters include; elastic modulus of steel and concrete, distribution and area of stirrups, width and depth of the beam.

\subsubsection{Displacement due to column rotation $\left(\Delta \delta_{i 4}\right)$}

$$
\Delta \delta_{i 4}=\frac{\Delta P_{i} L_{2} L^{2}}{12 E I_{y}}
$$

Where $L_{2}=$ Length of column

Total increment in displacement of the beam tip is then computed as sum of the displacements calculated using Eqns 10 to 14. Resulting expression for incremental load:

$$
\begin{aligned}
& \Delta P_{i}=K_{i} * \Delta \delta_{i}= \\
& {\left[f\left(L_{d}, E I_{y}, E I, \Delta P\right)+\frac{\left(L-L_{d}\right)^{3}}{3 E I_{y}}+\frac{1}{K_{s_{i}}}+\frac{L_{2} L^{2}}{12 E I_{y}}\right]}
\end{aligned}
$$

\subsection{Softening Factor $\left(R_{i}\right)$}

Based on the cohesive damage model for monotonic loads, cyclic load-displacement model is proposed by multiplying a softening factor $\left(R_{i}\right)$. This factor includes energy dissipation and loss of stiffness in previous load cycles i.e. to include the effect of load deformation history. Proposed load displacement relationship for concrete beam-column joints subjected to cyclic loads is:

$$
\Delta P_{i}=R_{i} * K_{i} * \Delta \delta_{i}
$$

A semi-analytical expression is developed for $R_{i}$. The softening factor depends on parameters such as loaddisplacement history, number of load cycles completed, displacement increments and confinement.

$$
R_{i}=\exp \left\{-C_{m} * N_{c} *\left(1+C_{h}^{2}\right)\right\}
$$

where, $R_{i}=$ Softening factor

$C_{m}=$ Empirical fragmentation factor

$N_{c}=$ Number of completed displacement cycles

$C_{h}=$ Displacement history factor

$$
C_{h}=\frac{d}{d_{h}+\Delta d}
$$

where, $\Delta d=$ Incremental displacement in the cycle;

$d=$ Total displacement in the present cycle

$d_{h}=$ Peak displacement in history

Three factors have been included in the present softening model- fragmentation of concrete, maximum displacement amplitude in the history, and the number of cycles experienced by the joint. The fragmentation factor is derived empirically and it depends upon the confinement provided. The displacement history factor is hyperbolic with the maximum displacement, explained previously (Eqn 18). Figure 7(a) presents variation of $C_{h}$ and $R_{i}$ with increasing $d_{h}$. $C_{h}$ asymptotically increases to unity as $\mathrm{d}_{h}$ increases, while $R_{i}$ diminishes and asymptotes to $0 . R_{i}$ decreases with the increase in number of loading cycles as presented in Figure 7(b), representing the enhanced softening with increased loads. $R_{i}$ includes the initiation and propagation of cracking as the loading progresses. Figure 7(c) combines the two effects and shows the variation of $R_{i}$ with both $C_{h}$ and $N_{c}$. It clearly shows the effects of $N_{c}, C_{h}$ and the combination of both on softening.

\section{RESULTS AND DISCUSSIONS}

Both the experimental and the analytical results have been compared in Figure 8. Comparison of Figures 8(a) and 8(b) indicates that close spacing of transverse 


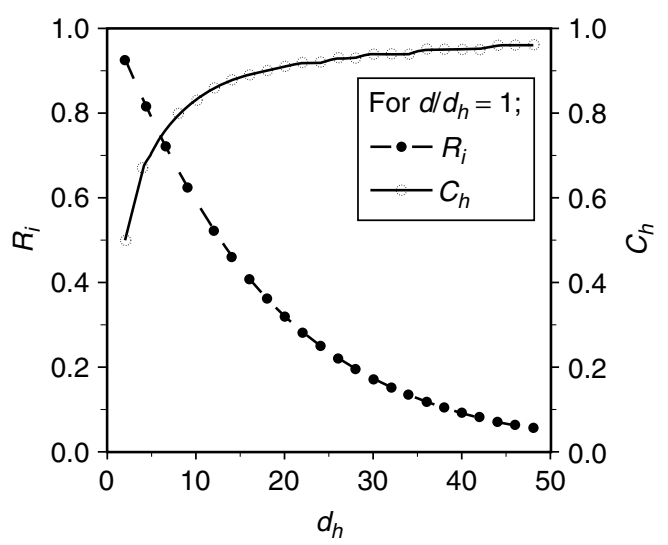

(a) $R_{i}$ and $C_{h}$ with $d_{h}$

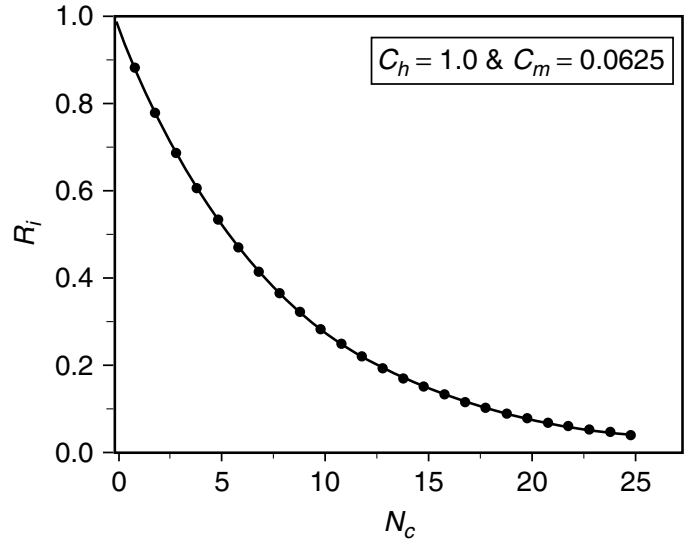

(b) $R_{i}$ with $N_{c}$

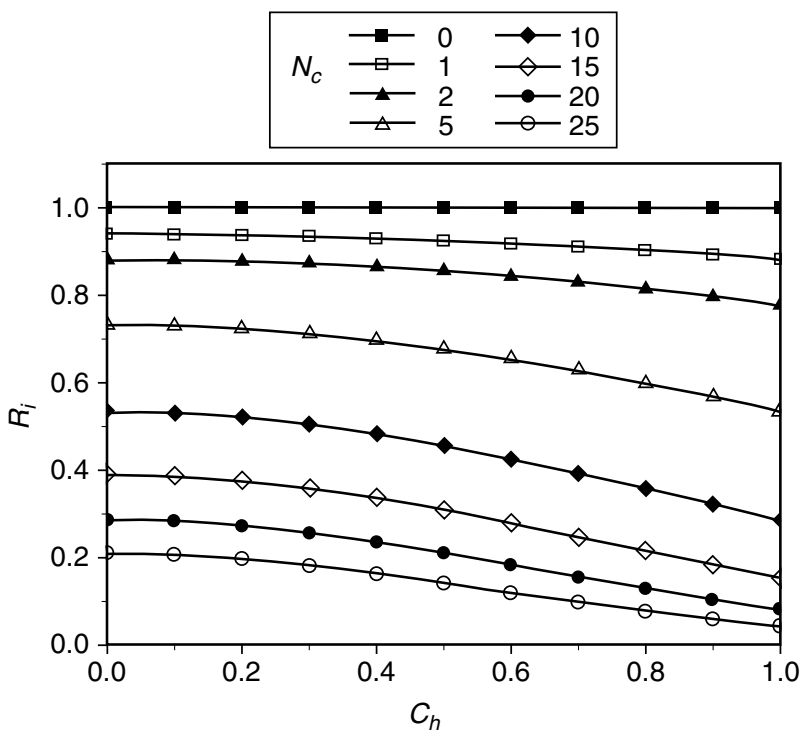

(c) $R_{i}$ with $N_{c}$ and $C_{h}$

Figure 7. Variation of softening factor $\left(R_{i}\right)$ with various parameters

reinforcement creates a more ductile behavior. Figure 8 (a) shows asymmetry in the experimental results in the positive and negative zones. This happened due to premature cracking and spalling of concrete in the positive zone. It finally led to fracture of one of the longitudinal reinforcing bars. Thus, it is clear that the brittle specimen can behave in an unpredictable manner. Although the analytical prediction matches closely with all other parts of the experimental curve the unloading of post reinforcement fracture of the brittle specimen is not captured by the present model. In all other specimens the theoretical and the experimental results have matched very closely.

Comparison between Figures 8(a) and 8(c) demonstrates that brittle joints can be effectively rehabilitated by FRP and improve their ductility. The unpredictable behavior of the brittle joint can also be controlled through FRP wrapping. Both the peak load and ultimate displacement have increased significantly through the rehabilitation.

Comparison of Figures 8(b) to 8(d) shows that the ductile joints can also be very effectively rehabilitated by the presented technique. The peak load increased from $30 \mathrm{kN}$ to $60 \mathrm{kN}$ through the CFRP wrap. The ultimate displacement also increased from $40 \mathrm{~mm}$ to $60 \mathrm{~mm}$. Thus the efficacy of the proposed system for both brittle and ductile joints is established.

Along with the envelope curves the loaddisplacement history of the entire loading cycles is presented in Figure 8. The agreement with the experiment and the proposed model is good. The difference in initial stiffness can be attributed to the inability of the model to capture the micro-cracking of concrete. Only in case of the control brittle joints there is deviation between the two results due to the fracture of steel rebar. The hysteresis predicted by the 

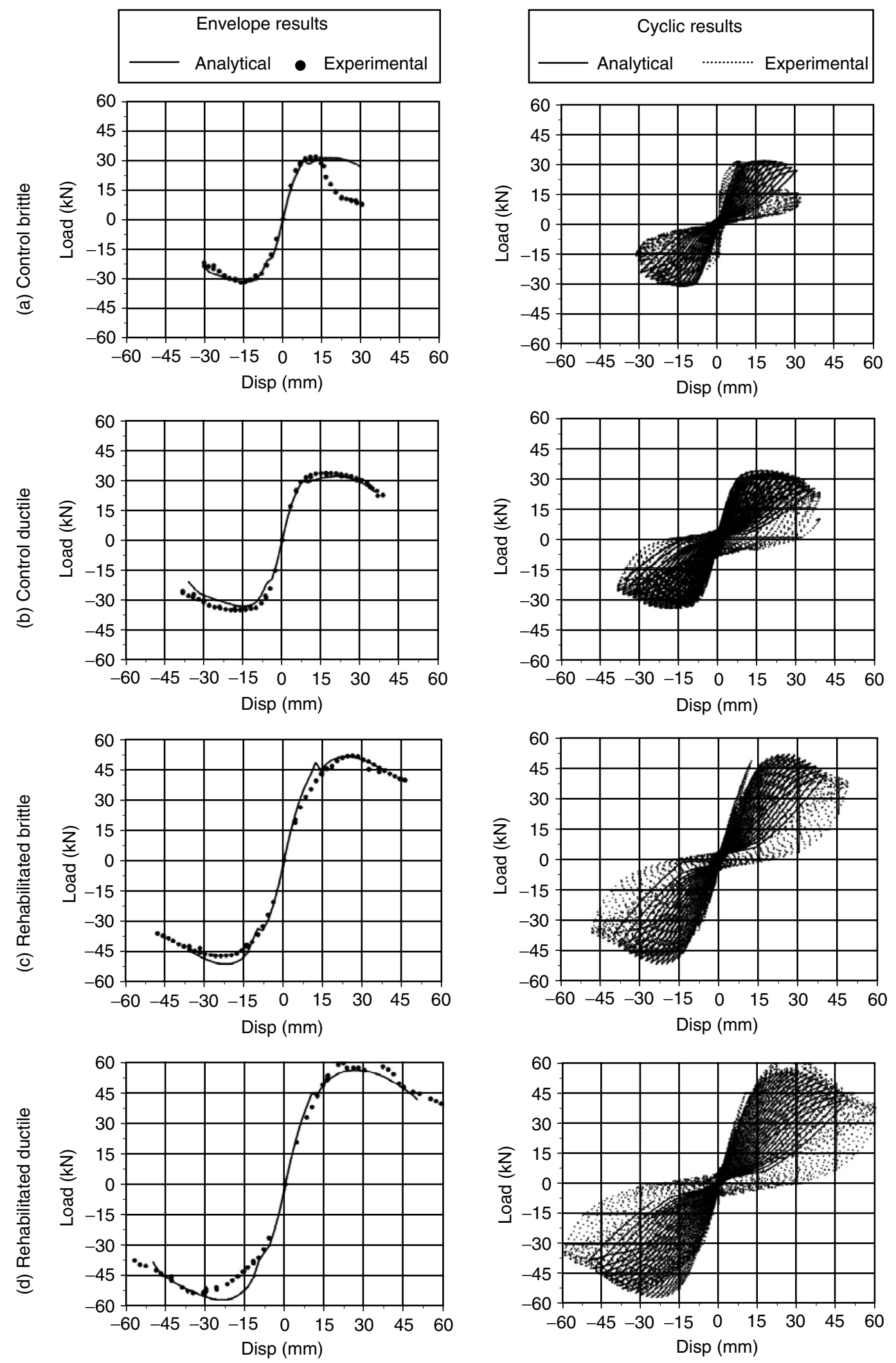

Figure 8. Comparison between analytical and experimental load - displacement result

model is lower than that experimentally observed. Thus, the model is conservative and it can be used for design of both control and rehabilitated reinforcement concrete joints.

\section{CONCLUSIONS}

This paper describes the performance of RC joints, both control and rehabilitated, under cyclic loading. Both experimental and analytical investigations have 
been reported. CFRP has been used in rehabilitation of the joints. Semi-analytical model for prediction of joint performance is proposed. The model accounts for confinement offered by the steel stirrups and FRP wraps. The contribution of both steel bars and externally bonded FRP has been considered for longitudinal reinforcement. It has been observed that it is feasible to rehabilitate $\mathrm{RC}$ joints that have been damaged to such an extent that their resistance to bending moment is completely exhausted. Both ductile and brittle joints can be rehabilitated by the proposed technique. The analytical model starts with the stress-strain behavior of constituent materials. The behavior of the resulting composite section is predicted by maintaining strain compatibility. The cross-sectional model is extended into the structural model. Cohesive model that incorporates damage through softening has been developed. Developed stiffness degradation model for FRP reinforced concrete beam-column joints subjected to cyclic loads have been discussed by the work presented. From results it may be concluded that:

(1) FRP rehabilitation is effective in improving both strength and ductility of RC joints. In the present experiments the ultimate load went up by $100 \%$ and ultimate displacement by $50 \%$.

(2) Analytical results agree with the experimental observations that FRP reinforcement improves load carrying capacity of RC beam - column joints significantly.

(3) Analytical results depict experimental fact that the FRP reinforcement improves ductile behavior of the system by allowing higher post yield load carrying capacity.

(4) Analytical model with cohesive damage and softening due to cyclic loads and energy dissipation can capture the softening behavior of joints in the post yield zone.

(5) The model is validated by comparing analytically obtained load-displacement for cyclically loaded joints with existing experimental results and they show good agreement.

(6) The method is useful for design of structural rehabilitation with targeted performance parameters such as initial stiffness, yield point, ultimate deformation and ultimate load.

(7) The procedure should be useful in the pushover analysis of RC frame structures that is oft used in earthquake resistant design.

The present investigation presents a model that includes the most significant parameters for design of rehabilitated joints with FRP. The analytical model presented here is a foundation on which several improvements could be made. The model should be tested for joints of other aspect ratios. In the present case, the size of the joint relative to the dimension of the members is small. For larger joints the joint deformations would be more pronounced. Thus, it may be necessary to explicitly model joint deformation. To validate such a model it will be necessary to measure joint deformation explicitly. The bar slip too may need to be explicitly modeled for heavily reinforced sections. The authors hope to report an improved model in near future.

\section{REFERENCES}

Abrams, D.P. (1987). "Scale relations for reinforced concrete beam-column joints", ACI Structural Journal, Vol. 84, No. 6, pp. 502-512.

Alcocer, S. and Jirsa, J.O. (1993). "'Strength of reinforced concrete frame connections rehabilitated by jacketing", ACI Structural Journal, Vol. 90, No. 3, pp. 249-261.

Antonopoulos, C.P. and Triantafillou, T.C. (2002). 'Analysis of FRP-strengthened RC beam-column joints', Journal of Composites for Construction, ASCE, Vol. 6, No. 1, pp. 41-51. Antonopoulos, C.P. and Triantafillou, T.C. (2003). "Experimental investigation of FRP-strengthened RC beam-column joints", Journal of Composites for Construction, ASCE, Vol. 7, No. 1, pp. $39-49$.

ASTM D-3039 (2006). Standard Test Method for Tensile Properties of Polymer Matrix Composite Materials, American Society for Testing and Materials, Pennsylvania, USA.

Clyde, C., Pantelides, C.P. and Reaveley L.D. (2000). Performance-Based Evaluation of Exterior Reinforced Concrete Building Joints for Seismic Excitation, Pacific Earthquake Engineering Research Report, PEER 2000/05, University of California, Berkeley, USA.

Dhakal, R.P., Pan, T.C., Irawan, P., Tsai, K.C., Lin, K.C. and Chen, C.H. (2005). "Experimental study on dynamic response of gravity designed RC connections", Engineering Structures, Vol. 27, No. 1, pp. $75-87$.

Durrani, A.J. and Wight J.K. (1985). "Behavior of interior beamto-column connections under earthquake - type loading", $A C I$ Journal Proceedings, Vol. 82, No. 3, pp. 343-349.

Filippou, F.C., Popov, E.P. and Bertero, V.V. (1986). "Analytical studies of hysteretic behavior of R/C joints", Journal of the Structural Engineering, ASCE, Vol. 112, No. 7, pp. 1605-1622.

Geng, Z.J., Chajes, M. J., Chou, T.W. and Pan, D.Y.C. (1998). "The retrofitting of reinforced concrete column-to-beam connections", Composites Science Technology, Vol. 58, No. 8, pp. 1297-1305.

Ghobarah, A. and El-Amoury, T. (2005). "Seismic rehabilitation of deficient exterior concrete frame joints", Journal of Composites for Construction, ASCE, Vol. 9, No. 5, pp. 408-416.

Ghobarah, A., Aziz, T.S. and Biddah, A. (1997). ' Rehabilitation of reinforced concrete frame connections using corrugated steel jacketing”, ACI Structural Journal, Vol. 94, No. 3, pp. 283-294. 
Ghobarah, A., El-Attar, M. and Aly, N.M. (2000). "Evaluation of retrofit strategies for reinforced concrete columns: A case study”, Engineering Structures, Vol. 22, No. 5, pp. 490-501.

Hanson, N.W. (1971). "Seismic resistance of concrete frames with grade 60 reinforcement", Journal of the Structural Division, ASCE, Vol. 97, No. 6, pp. 1685-1700.

Hanson, N.W. and Connor, H.W. (1967). "Seismic resistance of reinforced concrete beam-column joints", Journal of the Structural Division, ASCE, Vol. 93, No. 5, pp. 533-560.

Iacobucci, R.D., Sheikh, S.A. and Bayrak, O. (2003). "Retrofit of square concrete columns with carbon fiber-reinforced polymer for seismic resistance", ACI Structural Journal, Vol. 100, No. 6, pp. 785-794.

Lee, D.L., Wight, J.K. and Hanson, R.D. (1977). "RC beamcolumn joints under large load reversals", Journal of the Structural Division, ASCE, Vol. 103, No. 12, pp. 2337-2350.

Lowes, L.N. and Altoontash, A. (2003). "Modeling reinforcedconcrete beam-column joints subjected to cyclic loading", Journal of Structural Engineering, ASCE, Vol. 129, No. 12, pp. 1686-1697.

Lowes, L.N. and Moehle J.P. (1999). "Evaluation and retrofit of beam-column T-joints in older reinforced concrete bridge structure", ACI Structural Journal, Vol. 96, No. 4, pp. 519-532.

Meinheit, D.F. and Jirsa J.O. (1981). "Shear strength of R/C beam-column connections", Journal of the Structural Division, ASCE, Vol. 107, No. 11, pp. 2227-2244.

Mitra, N. and Lowes, L.N. (2004). "Evaluation and advancement of a reinforced concrete beam column joint model", Proceedings of the $13^{\text {th }}$ World Conference on Earthquake Engineering, Vancouver, B.C., Canada.

Mukherjee, A. and Joshi, M. (2005). "FRPC reinforced concrete beam-column joints under cyclic excitation", Composite Structures, Vol. 70, No. 2, pp. 185-199.

Mukherjee, A., Bagadi S.P. and Rai, G.L. (2009). "Semianalytical modeling of concrete beams rehabilitated with externally prestressed composites", Journal of Composites for Construction, ASCE, Vol. 13, No. 2, pp. 74-81.

Mukherjee, A., Boothby, T.E., Bakis, C.E., Joshi, M.V. and Maitra, S.R. (2004). "Mechanical behavior of fiber-reinforced polymerwrapped concrete columns - Complicating effects", Journal of Composites for Construction, ASCE, Vol. 8, No. 2, pp. 97-103.

Park, R. and Paulay, T. (1975). Reinforced Concrete Structures, John Wiley, New York, USA.

Park, R. and Ruitong, D. (1998). “A comparison of the behavior of reinforced concrete beam- column joints designed for ductility and limited ductility", Bulletin of the New Zealand National Society of Earthquake Engineering, Vol. 21, No. 4, pp. 255-278.

Parvin, A. and Granata, P. (2000). "Investigation on the effects of fiber composites at concrete joints", Composites Part B: Engineering, Vol. 31, No. 6-7, pp. 499-509.

Rai, G.L. (2007). Short-Term and Long-Term Performance of Externally Prestressed RC Beams and Joints, $\mathrm{PhD}$ Thesis, Department of Civil Engineering, IIT Bombay.
Sheikh, S.A. and Yau, G. (2002). "Seismic behavior of concrete columns confined with steel and fiber-reinforced polymers", ACI Structural Journal, Vol. 99, No. 1, pp. 72-80.

Triantafillou, T.C. and Antonopoulos, C.P. (2000). 'Design of concrete flexural members strengthened in shear with FRP", Journal of Composites for Construction, ASCE, Vol. 4, No. 4, pp. 198-205.

\section{NOTATION}

M moment

$\phi \quad$ curvature

$C_{f} \quad$ confinement factor

$E_{f} \quad$ modulus of elasticity of fiber

$E_{s} \quad$ modulus of elasticity of steel

$E_{0} \quad$ initial modulus of elasticity of concrete

$t_{f} \quad$ thickness of FRP wrap

$t_{s}$ effective thickness of confining steel reinforcement

effective radius of concrete core

width (smaller dimension) of the rectangular concrete section corner radius of the concrete section limiting strain in concrete stress in concrete strain in concrete secant modulus of concrete characteristic strength of concrete strain in compression steel strain in tension steel strain in compression FRP strain in tension FRP depth of neutral axis from top of compression surface compression force in $\mathrm{RC}$ section tension force in $\mathrm{RC}$ section stress in compression steel stress in compression laminate stress in concrete in compression cross sectional area of compression steel cross sectional area of compression FRP stress in tension steel stress in tension laminate cross sectional area of tension steel cross sectional area of tension FRP bending moment of resistance of compression concrete

$M_{s c} \quad$ bending moment of resistance of compression steel

$M_{f c} \quad$ bending moment of resistance of compression FRP

$M_{s t} \quad$ bending moment of resistance of tension steel

$M_{f t} \quad$ bending moment of resistance of tension FRP

$\Delta \phi \quad$ increment in curvature

$\delta \quad$ total displacement of the beam tip 


$\begin{array}{ll}U & \text { total strain energy } \\ U_{1} & \text { flexural strain energy } \\ U_{2} & \text { shear strain energy } \\ U_{3} & \text { axial strain energy } \\ \delta_{p} & \text { tip deflection in direction of load } P \\ P & \text { load on the beam tip } \\ P_{c} & \text { axial load in column } \\ L & \text { length of beam } \\ E & \text { elastic modulus } \\ G & \text { shear modulus } \\ I & \text { area moment of inertia of beam } \\ I_{c} & \text { area moment of inertia of column } \\ A_{c} & \text { cross sectional area of column } \\ A_{s} & \text { effective c/s area of beam in shear } \\ m_{c}(y) & \text { functional variation of moment on column for } \\ & \text { unit moment at joint-column interface } \\ L_{d} & \text { length of damage zone (Length of plastic hinge } \\ & \text { in beam) } \\ \Delta P_{i} & \text { incremental load in } i^{\text {th }} \text { step }\end{array}$

\begin{tabular}{|c|c|}
\hline$\Delta \delta_{i}$ & incremental displacement for $i^{\text {th }}$ step \\
\hline$\left[k_{i}\right]$ & stiffness matrix for $i^{\text {th }}$ step \\
\hline$P_{i}$ & total load at the beam tip after $i^{\text {th }}$ step \\
\hline$\delta_{i}$ & total displacement at the beam tip after the $i^{\text {th }}$ step \\
\hline$\Delta \delta_{i 1}$ & $\begin{array}{l}\text { displacement due to bending of the beam: in } \\
\text { damaged part }\end{array}$ \\
\hline$\Delta \delta_{i 2}$ & $\begin{array}{l}\text { displacement due to bending of the beam: in } \\
\text { undamaged part }\end{array}$ \\
\hline$E I_{y}$ & elastic flexural rigidity \\
\hline$E I$ & flexural rigidity at joint-beam interface \\
\hline$K_{s i}$ & shear Stiffness of beam for $i^{\text {th }}$ step \\
\hline$L_{2}$ & length of column \\
\hline$R_{\mathrm{i}}$ & softening factor \\
\hline$C_{m}$ & empirical fragmentation factor \\
\hline$N_{c}$ & number of completed displacement cycles \\
\hline$C_{h}$ & displacement history factor \\
\hline$\Delta a$ & incremental displacement in the cycle; \\
\hline a & total displacement in the present cycle \\
\hline$d_{h}$ & peak displacement in loading history \\
\hline
\end{tabular}

$\Delta \delta_{i} \quad$ incremental displacement for $i^{\text {th }}$ step

$P_{i} \quad$ total load at the beam tip after $i^{\text {th }}$ step

$\delta_{i} \quad$ total displacement at the beam tip after the $i^{\text {th }}$ step

$\Delta \delta_{i 1} \quad$ displacement due to bending of the beam: in damaged part

$\Delta \delta_{i 2}$ displacement due to bending of the beam: in

$E I_{y} \quad$ elastic flexural rigidity

EI flexural rigidity at joint-beam interface

$K_{s i} \quad$ shear Stiffness of beam for $i^{\text {th }}$ step

$L_{2} \quad$ length of column

$R_{\mathrm{i}} \quad$ softening factor

$C_{m} \quad$ empirical fragmentation factor

$N_{c} \quad$ number of completed displacement cycles

$C_{h} \quad$ displacement history factor

$d$ total displacement in the present cycle

$d_{h} \quad$ peak displacement in loading history 